\title{
0222 OCULAR INJURY AMONG WELDERS
}

F M Metwally*, S M El-Assal Correspondence: National Research Center, Tahrir Street, 12622 Dokki. Giza Egypt

10.1136/ip.2010.029215.222

Welders are an important occupational group in industrial Countries. Welding is a process of joining metals by melting and fusion and it is usually associated with cutting processes in many manufacturing operations. The study included 75 male welders and 100 male workers who had never been involved in welding operations as a control group. High prevalence rates of eye manifestations and abnormal ocular findings among welders were found by ophthalmological examination. The results of the study were attributed to the impact of non-ionizing radiation (ultraviolet and infrared) as well as flying metals in the working environment. Those with little experience, like young aged welders and those whose duration of work less than 5 years recorded the highest mean days off-work/year due to photophthalmia and/or eye foreign body injury. Eye protective devices and educational programs stressing the importance of wearing them are essential. 